\title{
Editorial
}

Spinal Cord (2002) 40, 551. doi:10.1038/sj.sc.3101371

\section{Rugby Union}

Rugby Union at the top level became a professional sport in 1995 following an announcement from the International Rugby Board that the game would become professional. This has resulted in the top players becoming highly paid professional athletes and most becoming full-time sportsmen. The intensity of training has therefore increased, and the impact between players dramatically increased due to increased size, speed and power.

I was concerned as an International rugby player at the start of my Othopaedic career by the number of neck injuries occurring in rugby union football. This led to a publication in the British Medical Journal in December 1978, with Professor Brian McKibbin suggesting possible ways of preventing serious neck injuries. It appeared to us that these happened mainly in teenage rugby players, resulting in catastrophic long-term complications.

Dr John Silver has done a lot of work in the same area and I am glad to see he has contributed an excellent article in this Edition. As a result of all the work, there have been major changes in scrummagging laws, and this has resulted in a decrease in traumatic neck injuries in Rugby Union Football.

We have also seen a dramatic increase in the amount of protective wear worn in rugby union, and in particular shoulder pads and head gear. The use of mouth guards has been in existence for many years and I personally wore a mouth guard throughout my career, and I am glad to say this saved my teeth on many occasions! It is interesting that not all professional players wear protective mouth guards and I find this incredible. As to the shoulder and head guards, the jury is still out as to whether, in fact, these do not lead to an increased number of injuries. In particular, head guards lead players to have a lack of fear when going in to tackle, ruck or maul. This may result in an increased number of facial lacerations and neck injuries. It was shown in American football that following the introduction of hard helmets to prevent head injuries the number of neck injuries increased dramatically.

Any bleeding on a player results in them being removed from the field of play to sit in the 'blood bin' until the blood flow has been stemmed. This is obviously a sensible precaution in view of blood borne infections, and in particular the worry over HIV. At present, as far as I am aware, rugby union players do not have to take HIV blood tests before being allowed to participate.

As in all branches of medicine, prevention is better than cure, and in an increasingly physical game such as rugby union the chance of serious injury has to be minimised. Prophylactic taping of ankles, thumbs and wrists are common place and protective gear is available for head, shoulders, lumbar spine, elbow, knee and ankle.

In spite of all these protective aids, it is still vitally important to have fit rugby players at whatever level they compete. The fitter the player, the less likely he is to be injured. It beholds us all to do as much as we can in the way of research in a quest to reduce the number of serious injuries in this highly competitive and physical contact sport.

Mr JPR Williams is a Consultant Orthopaedic Surgeon. He is an international rugby player who represented Wales on more than 50 occasions and was a member of the British Lions Rugby team touring New Zealand and South Africa.

JPR Williams, MBE, FRCS Ed Bridgend Sports Clinic Foundation, Llansannor Lodge, Llansannor, Cowbridge CF7 7RX 